\title{
GAMBUS TUNGGAL EDI PULAMPAS DI PEKON BANJAR NEGERI-LAMPUNG
}

\author{
Nofriyan Hidayatulloh \\ Program Studi S-1 Etnomusikologi ISI Yogyakarta \\ Email: nofriyanhidayatulloh@yahoo.co.id
}

\begin{abstract}
Abstrak
Gambus Tunggal adalah kesenian tradisional masyarakat Lampung pesisir yang dimainkan oleh satu sampai dua orang. Jika dimainkan oleh satu orang, maka si pemain gambus akan merangkap sebagai vokal. Jika dimainkan oleh dua orang, maka satu sebagai pemain gambus dan satu sebagai vokal, terkadang terjadi duet. Lirik dari lagu gambus tunggal adalah seni sastra Lampung yang berbentuk Bebandung. Bebandung yaitu suatu sastra yang berupa karangan puisi yang disusun seperti pantun dengan pola rumus $a b-a b$. Isinya dapat berupa cerita dan dibacakan dengan berlagu dengan penuh perasaan dan penghayatan, hingga yang mendengar seperti ikut di dalam cerita tersebut. Lirik yang dibawakan pada umumnya menceritakan seputar kehidupan sehari-hari dan percintaan. Edi Pulampas adalah salah satu tokoh gambus dari Pekon Banjar Negeri, Lampung yang mempopulerkan lima bentuk penyajian gambus, yakni bentuk penyajian gambus tunggal yang dimainkan secara solo, bentuk penyajian lagu gambus yang dipindahkan ke instrumen gitar, bentuk penyajian gambus dengan biola, bentuk penyajian gambus dengan alat musik rebana, accordion, dan gong sebagai iringan tari bedana sampai bentuk penyajian lagu gambus yang didangdutkan hingga menjadi lagu dangdut Lampung yang khas. Kesenian gambus tunggal Edi Pulampas biasanya dimainkan pada acara-acara hajatan, seperti acara pernikahan dan khitanan. Ada dua rumusan masalah yang diangkat pada penelitian ini, yaitu bagaimana bentuk penyajian gambus tunggal Edi Pulampas dan apa fungsi gambus tunggal Edi Pulampas pada masyarakat pekon Banjar Negeri Lampung. Metode penelitian yang digunakan adalah metode penelitian kualitatif, yaitu penelitian yang difokuskan pada gejala-gejala umum yang ada dalam kehidupan manusia dan menggunakan pendekatan etnomusikologis. Pendekatan etnomusikologis yaitu suatu pendekatan yang membahas tentang persoalan musik dalam budaya masyarakat. Berdasarkan pendekatan tersebut, kesenian gambus tunggal Edi Pulampas memiliki beberapa fungsi dalam masyarakat Lampung, dalam konteks acara pernikahan orang Lampung. Pada acara tersebut, kesenian gambus tunggal disajikan secara vokal instrumental. Kesenian ini memiliki fungsi dalam masyarakat Lampung sebagai hiburan pribadi, presentasi estetis, dan sebagai media komunikasi.
\end{abstract}

Kata kunci: Gambus dan kreativitas Edi Pulampas.

\begin{abstract}
Gambus Tunggal is a traditional art of the coastal Lampung community which is played by one to two people. If played by one person, then the gambus player will double as a vocal. If played by two people, then one as a gambus player and one as a vocal, sometimes a duet occurs. The lyrics of the gambus tunggal song are Lampung literary art in the form of Bebandung. Bebandung is a literary form in the form of poetry composed like rhymes with the formula pattern $a b-a b$. The contents can be in the form of stories and are read with a song full of feelings and appreciation, so that the listeners like to participate in the story. The lyrics that are delivered generally tell about daily life and romance. Edi Pulampas is one of the gambus figures from Pekon Banjar Negeri, Lampung who popularized the five forms of gambus presentation, namely the form of presentation of a single gambus that was played solo, the form of presenting the song of gambus transferred to a guitar instrument, the form of presentation of gambus with violin, the form of presentation of gambus with rebana, accordion, and gong as bedana dance accompaniment to the form of gambus song that is sung to become a distinctive Lampung dangdut song. Gambus Tunggal's art Edi Pulampas is usually played on celebration events, such as weddings
\end{abstract}


and circumcisions. There are two formulations of the problem raised in this study, namely how the form of presentation of the Edi Pulampas single gambus and what is the function of the Edi Pulampas single gambus in the community of Banjar Negeri Lampung. The research method used is a qualitative research method, namely research that is focused on general symptoms that exist in human life and uses an ethnomusicological approach. Ethnomusicological approach is an approach that discusses the problem of music in the culture of society. Based on this approach, Edi Pulampas's solo gambus art has several functions in Lampung society, in the context of Lampung people's weddings. At the event, gambus tunggal art was presented vocally instrumental. This art has a function in Lampung society as personal entertainment, aesthetic presentation, and as a medium of communication.

Keywords: Gambus and Edi Pulampas Creativity.

\section{A. Latar Belakang}

Gambus merupakan alat musik petik melayu yang berasal dari peradaban Islam di Timur-Tengah (gambus dalam bahasa Arab disebut u'd atau oud) (Musmal, 2010:2). Alat musik ini berkembang di kalangan masyarakat Lampung pesisir yang beradat sai batin. Lampung terbagi atas dua sistem adat, yakni adat pepadun dan adat sai batin, kedua sistem adat ini diklasifikasikan dari dialek bahasa masyarakatnya. Dialek nyow bagi masyarakat adat pepadun dan dialek api bagi masyarakat adat sai batin. Pembagian dialek ini dilakukan oleh Dr. J.W. van Royen pada akhir abad ke-IX saat masa pemerintahan Hindia-Belanda (Ainun Mahya, 2016:5). Nyow bagi adat pepadun dan api bagi adat sai batin, merupakan bahasa masing-masing adat yang dalam bahasa Indonesia berarti "apa". Kesenian gambus tunggal yang berkembang pada masyarakat pesisir yang beradat sai batin, adalah kesenian tradisi yang dimainkan oleh satu orang yang bernyanyi sambil bermain gambus. Dalam perkembangannya, kesenian gambus mulai dimainkan oleh dua orang dan tidak menutup kemungkinan untuk dikolaborasikan dengan alat musik lain.

Edi Pulampas adalah tokoh gambus dari pekon (desa) Banjar Negeri Lampung yang mempopulerkan lima bentuk penyajian gambus ke ranah entertainment. Edi Pulampas yang bernama asli Edi Yanto terlahir di pekon Sukamerindu Kecamatan Talang Padang, Kabupaten Lampung Selatan pada tanggal 08 Juni 1956. Sejak muda Edi Pulampas memang sudah aktif berkecimpung di dalam kesenian tradisi Lampung khususnya kesenian gambus tunggal. Nama Edi mulai dikenal di Lampung sejak tahun 1978 dengan solo pertama yang berjudul Pulipang. Lagu ini diciptakan pada tahun 1978 dan popular di Lampung pada akhir tahun 1979. Hingga sekarang Edi terus menggeluti kesenian gambus tunggal Lampung, Edi mulai melakukan inovasi dalam mengemas bentuk penyajian kesenian gambus tunggal 
Lampung, sebagai langkah dalam mewujudkan kreativitas.

Prestasi Edi antara lain adalah pentas di Istana Negara pada tanggal 17 Agustus tahun 1984 dalam acara Parade Musik Nusantara yang diselenggarakan dalam rangka memperingati Hari Kemerdekaan Republik Indonesia. Pada tahun yang sama, Edi bersama kawankawan Taman Budaya berangkat ke Belanda sebagai salah satu Duta Seni dari Lampung mewakili Indonesia. Tidak hanya ke Belanda, pada tahun 1987 Edi juga berangkat ke Brunei dan Malaysia sebagai salah satu Duta Seni dari Lampung yang mewakili Indonesia. Setahun kemudian, pada tahun 1988, Edi tampil sebagai pengisi acara Musabaqah Tilawatil Quran di stasiun Radio Republik Indonesia Lampung. Pada tahun 1993, Edi tampil dalam acara Festival Musik Tradisional tingkat Nasional di Taman Ismail Marzuki. Waktu itu, Edi dan kawan-kawan mewakili provinsi Lampung dengan menampilkan musik gambus Lampung yang dikolaborasikan dengan alat musik rebana, kulintang, biola, dan bass elektrik, dengan judul garapan Klasik Musik Gambus Tradisional. Tahun 2008 Edi dipanggil untuk rekaman lagu-lagu gambus tradisional Lampung dalam rangka pendokumentasian di Kantor Pemerintah Daerah Kabupaten Tanggamus. Tahun 2010, Edi menjadi pembicara dalam acara
Sarasehan Musik Tradisional dan Sastra Lampung di Taman Budaya Provinsi Lampung. Tahun 2017, Edi tampil di Taman Mini Indonesia Indah bersama Kabupaten Lampung Barat. Pada tahun 2017 ini juga Edi mendapatkan piagam penghargaan dari walikota Bandar Lampung sebagai seniman Lampung yang melestarikan seni budaya Lampung. Pada tahun ini, Edi juga sempat mengajar musik gambus selama kurang lebih tiga bulan di dua SMP di Kecamatan Gunung Alip dalam program Gerakan Seniman Masuk Sekolah. Menurut Edi, melihat respon anak-anak yang cukup antusias, Edi mulai membuka kelas gambus Lampung di rumahnya yang baru berjalan satu tahun belakangan. Tahun 2018, Edi kembali dipanggil untuk tampil di stasiun radio RRI Lampung dan pada tahun 2019, Edi menjadi juri Liga Dangdut se-Kabupaten Tanggamus.

Selain itu, Edi juga sudah merekam beberapa album pribadinya, yaitu album Anak Ngukha pada tahun 1985, album lagu dangdut Lampung Mamak Inut pada tahun 1988 dan album Khasan Sayuk pada tahun 2011 sampai yang terakhir adalah rekaman beberapa solo pada tahun 2012. Ada juga beberapa album kompilasi Edi bersama rekan musisi Lampung lainnya. Semenjak merebaknya pembajakan kaset, Edi mulai meninggalkan dapur rekaman dan lebih sering tampil dalam acara-acara hajatan seperti pernikahan, sunatan dan syukuran 
baik di Lampung, Palembang sampai di Bengkulu dan sempat tampil juga beberapa kali dalam rangka ulang tahun kabupaten Tanggamus dan acara-acara di kota Bandar Lampung. Lagu-lagu yang diciptakan Edi banyak terinspirasi dari kehidupan masyarakat di sekitarnya. Menurut Edi, hal yang tersulit dalam menciptakan sebuah lagu gambus tunggal adalah pencarian nadanya atau musik iringan gambusnya, karena menurut Edi, setiap kata-kata memiliki nadanya sendiri.

\section{B. Metode Penelitian}

Dalam penelitian ini metode yang digunakan adalah metode penelitian kualitatif. Bogdan dan Taylor (1975:5) mendefinisikan metodologi kualitatif sebagai prosedur penelitian yang menghasilkan data deskriptif berupa katakata tertulis atau lisan dari orang-orang dan perilaku yang dapat diamati (Lexy J Moleong, 2006:4). Penelitian ini menggunakan pendekatan

Etnomusikologis. Etnomusikologis merupakan pendekatan multi disiplin, karena dalam pendekatan ini menggunakan beberapa disiplin ilmu lain yang dibutuhkan peneliti dalam penelitiannya. Disiplin ilmu lain yang digunakan adalah Sosiologis untuk membantu peneliti saat membahas kesenian gambus tunggal dalam masyarakat dan Historis untuk membahas perjalanan karir Edi Pulampas selaku tokoh yang diangkat dalam penelitian ini. Objek penelitian adalah kesenian gambus tunggal di pekon Banjar Negeri, Lampung. Edi Pulampas sebagai tokoh gambus yang melakukan inovasi dalam mengemas bentuk penyaian gambus. Sebagai langkah dalam mewujudkan kreativitasnya.

Teknik pengumpulan data yang digunakan yakni, studi pustaka, observasi, wawancara, dan dokumentasi. Ada dua sumber pustaka, yakni Perpustakaan Institut Seni Indonesia Yogyakarta dan buku koleksi pribadi peneliti. Observasi dilakukan di pekon Banjar Negeri, Kecamatan Gunung Alip, Kabupaten Tanggamus, Provinsi Lampung. Ada dua narasumber utama yang dipilih peneliti, yaitu Edi Pulampas sebagai pelaku kesenian gambus tunggal Lampung, pencipta lagu dan sebagai tokoh yang memperkenalkan gambus tunggal Lampung di ranah entertainmen atau hiburan dan datuk Sukhai selaku pemain dan pembuat gambus di pekon Banjar Negeri. Proses dokumentasi pada penelitian ini dilakukan dengan cara mengumpulkan data berupa foto, video, dan rekaman suara pada saat wawancara. Proses dokumentasi dilakukan saat wawancara dan saat penampilan gambus tunggal Edi Pulampas di acara pernikahan.

Untuk menganalisis data, baik data tekstual dan kontekstual menggunakan metode sampling yang akan membahas 
pokok suatu musik dalam sebuah penelitian. Metode ini dikemukakan oleh Rahayu Supanggah dalam buku Etnomusikologi. Dalam buku tersebut dikemukakan terdapat dua pilihan untuk menganalisis suatu data tekstual, yaitu dengan penggunaan notasi yang detail atau notasi yang sifatnya hanya mencatat kerangka-kerangkanya saja. Penelitian ini menggunakan notasi yang bersifat kerangka-kerangkanya saja. Data yang sudah terkumpul melalui observasi, wawancara, studi pustaka dan dokumentasi, selanjutnya diseleksi berdasarkan fakta yang dianalisa dan dievaluasi secara cermat untuk mempermudah klasifikasi objek penelitian sesuai dengan permasalahan. Langka-langkah yang digunakan berupa pemilihan data, klasifikasi data, penyajian data, pengumpulan data, penafsiran dan pengambilan kesimpulan. Data-data yang terkumpul dipilih dan dikelompokan menjadi data pokok (primer) dan data penunjang (sekunder).

\section{Hasil dan Pembahasan}

Kesenian gambus tunggal Lampung adalah jenis kesenian yang dimainkan secara solo atau sendirian, namun dalam perkembangannya kesenian gambus ini mulai dimainkan oleh dua orang atau lebih. Berawal dari kesenian tradisional masyarakat Lampung, musik gambus Lampung sudah mulai masuk panggung pertunjukan dan dikemas ke dalam kemasan yang lebih modern dan tidak menutup kemungkinan untuk dikolaborasikan dengan alat musik lain. Bentuk penyajian kolaborasi ini yang Edi coba tularkan kepada masyarakat luas. Edi mempopulerkan lima bentuk penyajian gambus, yakni bentuk penyajian gambus yang dimainkan secara solo, bentuk penyajian gambus yang dipindahkan ke media gitar, bentuk penyajian gambus dengan biola, bentuk peyajian gambus dengan rebana, accordion, dan gong sebagai musik iringan tari bedana, sampai bentuk penyajian lagu gambus yang didangdutkan hingga menjadi lagu dangdut Lampung yang khas. Bentuk penyajian yang akan dianalisis adalah bentuk bentuk penyajian gambus Edi Pulampas yang dimainkan secara solo sebagai hiburan di acara pernikahan yang di dokumentasikan pada tanggal 04 april 2019.

1. Bentuk Penyajian gambus Edi Pulampas yang dimainkan secara Solo

Bentuk penyajian gambus ini biasa diawali dengan permainan improvisasi gambus. Setelah improvisasi, gambus akan memainkan melodi pengantar masuknya vokal. Disetiap sela dalam satu baitnya, gambus akan memainkan melodi pendek untuk jeda sebelum masuk ke bait selanjutnya dan setiap sela dua bait, biasanya gambus akan memainkan melodi 
yang lebih panjang dibandingkan sela dalam satu baitnya dan begitu seterusnya sampai kepada bait penutup. Setelah bait penutup biasanya gambus akan memainkan melodi untuk menutup lagunya. Lagu yang dijadikan sampel adalah lagu yang berjudul
Saka Mak Tungga. Lagu ini dibawakan Edi sebagai hiburan di acara pernikahan pada tanggal 04 April 2019 di Lampung. Lagu ini dijadikan sampel lagu yang akan dianalisis.
Stem Gambus Edi Pulampas pada Lagu Saka Mak Tungga

$\begin{array}{cccccc}\text { senar } & \text { senar } & \text { senar } & \text { senar } & \text { senar } & \text { senar } \\ 6 & 5 & 4 & 3 & 2 & 1 \\ \text { D } & \text { G } & \text { B } & \text { E } & \text { A } & \text { D }\end{array}$

Catatan: Berdasarkan nada diatas, nada root berada di nada E, tapi dalam prakteknya, nada root tidak pas di nada $\mathrm{E}$ pada musik Barat, nada root berada di antara nada $\mathrm{E}$ dan $\mathrm{F}$.
Tangga nada yang digunakan pada lagu Saka Mak Tungga adalah tangga nada minor dengan scale prhygian . Jadi urutan tangga nadanya, mi-fa-sol-la-si-do-re-mi', dan interval yang tersusun menjadi $1 / 2-1-1-$
1-1/2-1-1. Contohnya, jika dimainkan pada tangga nada natural (C Mayor), maka nada ke tiga (E) yang menjadi nada root, sehingga tangga nadanya menjadi E-F-GA-B-C-D-E'.

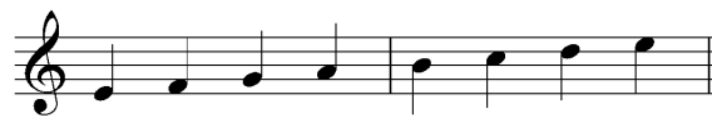

Dari segi interval, tangga nada pada lagu Saka MakTungga sama dengan tangga nada di atas, tetapi dari segi ketepatan nada, penjelasan di atas adalah nada-nada yang mendekati. Jika disandingkan dengan salah satu maqam pada gambus arab, maka tangga nadanya mirip dengan maqam bayati. Dinamika dan tempo pada lagu Saka Mak Tungga, dibangun dari emosi si pemain dan isi lirik yang disampaikan.
Dinamika pada lagu Saka Mak Tungga tergolong stabil dengan tempo yang sedang yaitu Moderato (96-104 M.M). Ritme pada lagu Saka Mak Tungga sangat berkaitan erat dengan teknik gambusnya. Hal ini dikarenakan, alat musik gambus berperan sebagai pembawa irama. Degupan atau irama dari gambus yang dimainkan secara teratur dan berulang-ulang menciptakan suatu ritme. Teknik yang digunakan pada lagu Saka Mak Tungga adalah gabungan antara teknik Humbak Molokh dan Khiyuk 
Pagi. Lagu Saka Mak Tungga tergolong lagu satu bagian (bagian A), yang terdiri dari dua belas motif dan enam kalimat. Motif-motif yang tersusun membentuk kalimat tanya dan kalimat jawab yang
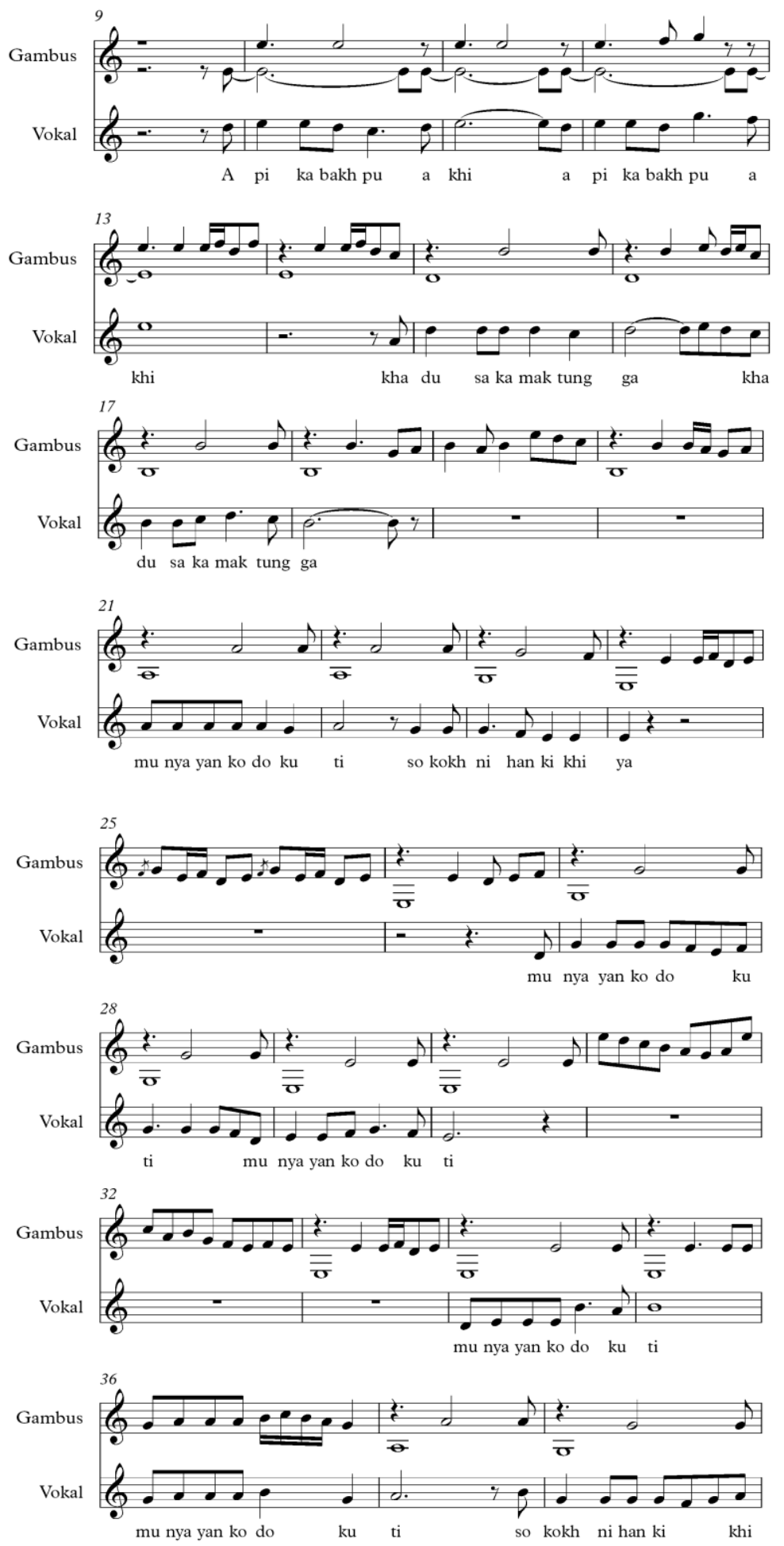


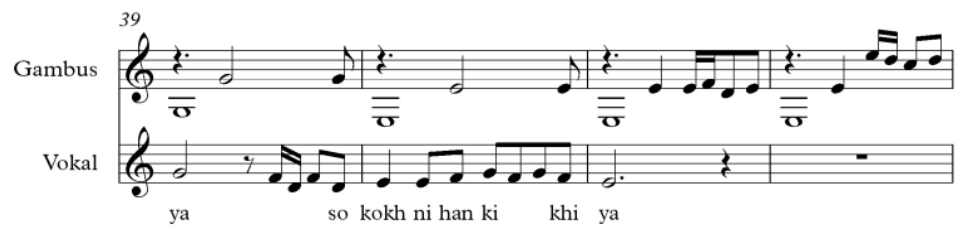

Struktur lagu Saka Mak Tungga (sekuens), pembesaran interval adalah intro-bagian A-intro-bagian A-intro(augmentation of the ambitus), pengecilan bagian A-intro-bagian A. Berlandaskan interval (diminuation of the ambitus), analisis bentuk musik dari Karld-Edmund pembalikan (inversion), pembesaran nilai Pier SJ, dalam bukunya Ilmu Bentuk nada (augmentation of the value) dan Musik, membagi motif menjadi tujuh dalam pengolahannya, yakni ulangan pengecilan niai nada (diminuation of the value).

harafiah, ulangan pada tingkat lain

kalimat tanya

$\mathrm{m}$
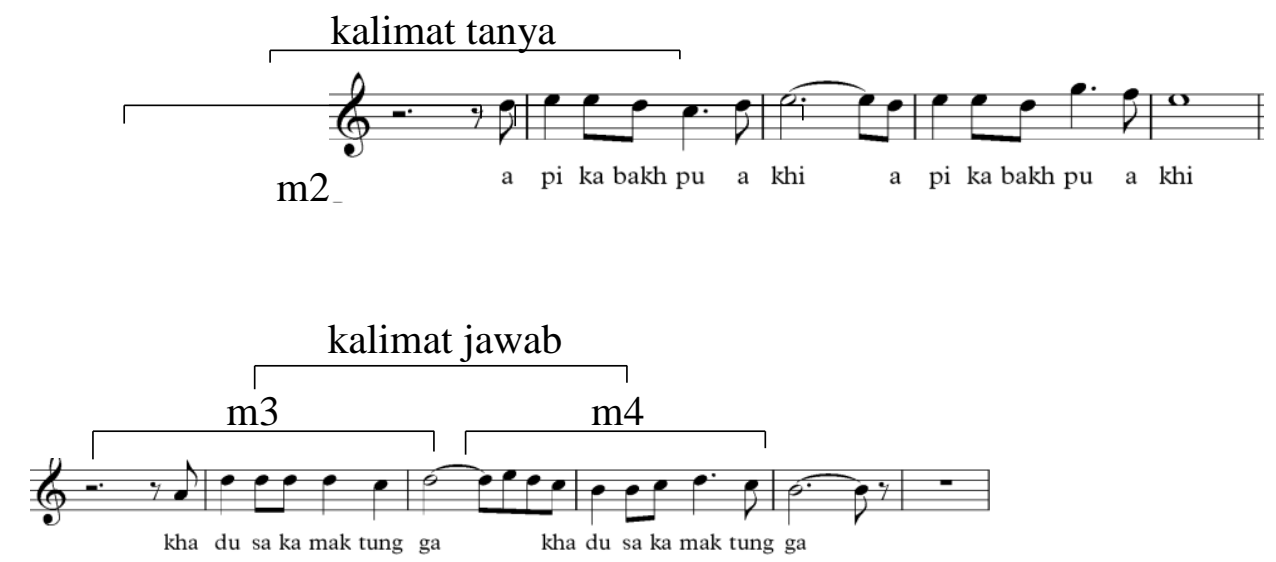

kalimat tanya

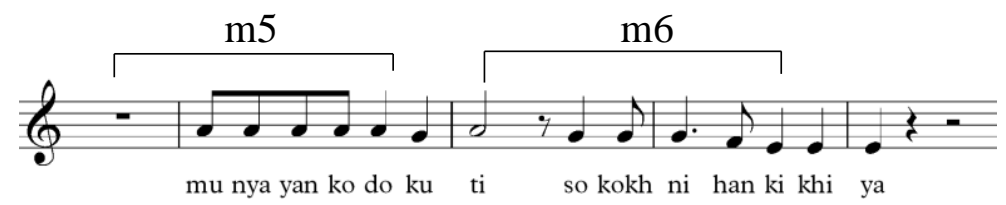

kalimat jawab

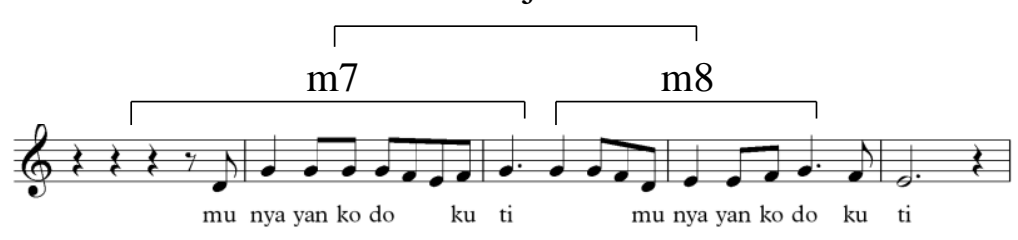

kalimat tanya

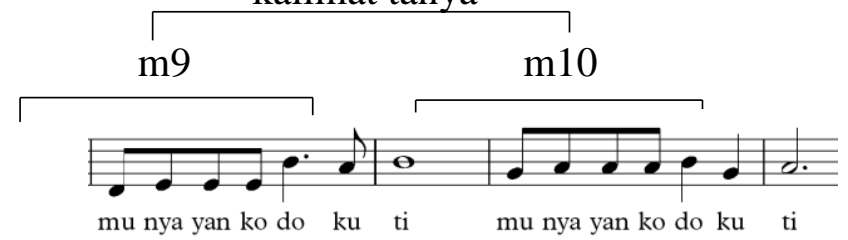

kalimat jawab

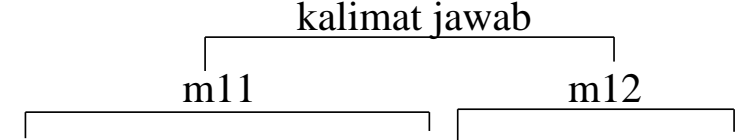




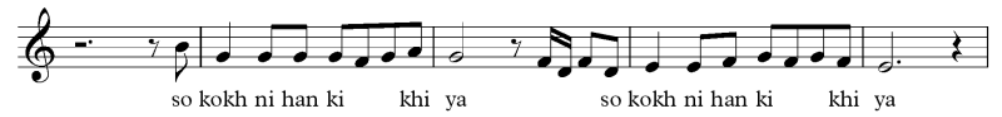

Pada m (motif pokok) dan m2 (motif 2) terjadi ulangan pada tingkat lain (sekuens naik) dan terjadi juga pembesaran nilai nada.

Pada m (motif pokok) dan m3 (motif 3) terjadi pembesaran interval.

Pada m (motif pokok) dan m4 (motif 4) terjadi pembesaran nilai nada.

Pada m (motif pokok) dan m5 (motif 5) terjadi pengecilan nilai nada.

Pada m (motif pokok) dan m6 (motif 6) terjadi pembesaran nilai nada.

Pada $\mathrm{m}$ (motif pokok) dan $\mathrm{m} 7$ (motif 7) terjadi pengecilan nilai nada.

Pada m (motif pokok) dan m8 (motif 8) terjadi pembalikan.

Pada m (motif pokok) dan m9 (motif 9) terjadi pengecilan nilai nada.

Pada m (motif pokok) dan m10 (motif 10) terjadi pengecilan nilai nada.

Pada m (motif pokok) dan m11 (motif 11) terjadi pengecilan nilai nada.

Pada m (motif pokok) dan m12 (motif 12) terjadi pengecilan nilai nada.

Dari pemaparan di atas:

m dan $\mathrm{m} 2 \quad$ - kalimat 1 (kalimat tanya)

m3 dan m4 - kalimat 2 (kalimat jawab)

m5 dan m6 - kalimat 3 (kalimat tanya)

m7 dan m8 - kalimat 4 (kalimat jawab)

m9 dan m10 - kalimat 5 (kalimat tanya)

m11 dan m12 - kalimat 6 (kalimat jawab)

Lirik yang digunakan pada lagu

Saka Mak Tungga tergolong dalam sastra Lampung yang berbentuk bebandung.

Bebandung adalah suatu sastra berupa suatu karangan puisi yang disusun seperti pantun yakni selalu berakhir dengan pola rumus a b - a b. Isinya dapat berupa cerita dan dibacakan dengan berlagu dengan penuh perasaan dan penghayatan, sehingga yang mendengarnya akan seperti ikut di dalam cerita tersebut (Hasyimkan, Tesis S2 tahun 2017:71). Pada lagu Saka Mak Tungga, liriknya menceritakan satu peristiwa yang terjadi mengenai seseorang yang kembali bertemu dengan saudaranya setelah sekian lama tidak pernah bertemu karena kesibukan masing-masing. Keduanya tidak sempat untuk saling memberi kabar dan tidak sempat untuk saling mencari tahu kabar keduanya. Ketika mereka dipertemukan disalah satu peristiwa, keduanya saling menyapa, bergembira, mendoakan satu sama lain dan memaklumi satu sama lain. Lirik lagu saka mak tungga tergolong pada bentuk puisi yang bersajak A B A B. 
Bentuk sastra lirik Saka Mak Tungga

Bait Pertama :

Api kabakh puakhi

Khadu saka mak tungga

Munyayan kodo kuti

Sokokh nihan ki khiya

Bait Ke dua

Kham tungga dawah hinji

Bugukhau lalang waya

Tok ko na sebik hati

Dija pantun jejama

Bait ke tiga

Senang khasani hati

Kham dapok tungga dija

Induh kapan Masani

Kham dapok molokh tungga

Bait ke empat

Sedong saka ni jaman

Kita mak selang kata

Gedahni man mak kandan

Mula ya ku di dija

Lirik lagu Saka Mak Tungga terbagi menjadi empat bait. Bait pertama adalah bait pembuka, bait kedua dan ketiga adalah isi atau ungkapan hati ketika bertemu dan bait keempat adalah kesimpulan atau saling memahami satu sama lain/saling maklum.

2. Fungsi Gambus Tunggal Edi Pulampas Pada Masyarakat Pekon Banjar Negeri

Pada awal perkembangannya, gambus tunggal Lampung berfungsi sebagai hiburan pribadi sebagai ungkapan isi hati si pelantunnya, yang biasa dimainkan untuk mengisi waktu senggang di sela-sela pekerjaan dan dipakai oleh mekhanai dalam acara muli mekhanai dan manjau muli. Sejak tahun 1990-an, gambus tunggal Lampung mulai masuk ke ranah
Terjemahan Bebas

Apa kabar saudara

Sudah lama tak jumpa

Sehatkah kalian

Syukur sekali jika begitu

Kita bertemu siang ini

Bercanda riang gembira

Hilangkan rasa sedih

Mari berpantun bersama

Senang rasanya hati

Kita dapat berkumpul di sini

Entah kapan waktunya

Kita dapat bertemu lagi

Sangat lama kita tak bertemu

Kita tidak saling bicara

Memanglah kita tidak saling peduli

Karena itulah aku di sini

entertainment dan lebih berfungsi sebagai sarana hiburan dan presentasi estetis. R.M. Soedarsono membagi fungsi seni pertunjukan menjadi dua, yaitu fungsi primer dan fungsi sekunder. Fungsi primer dari seni pertunjukan apabila seni tersebut jelas siapa penikmatnya. Hal ini berarti bahwa seni pertunjukan disebut sebagai seni pertunjukan karena dipertunjukkan kepada penikmat. Apabila seni pertunjukan tersebut bertujuan bukan sekedar untuk dinikmati tetapi untuk kepentingan yang lain, fungsinya adalah sekunder (R.M. Soedarsono, 2001:170). Fungsi primer dibagi menjadi tiga yaitu sebagai sarana ritual, sebagai hiburan pribadi dan sebagai representasi estetis (R.M. Soedarsono, 2002:123). Dengan demikian, gambus 
tunggal Edi Pulampas memiliki dua fungsi primer dan satu fungsi sekunder, yaitu:

a. Sebagai Hiburan Pribadi

Fungsi gambus sebagai hiburan pribadi dapat terjadi ketika gambus dimainkan di panggung pertunjukan. Ketika ada penonoton yang maju ke panggung untuk request lagu dan bernyanyi, dengan kata lain ketika ada penonton yang ikut terlibat di dalam pertunjukan gambus, maka gambus berfungsi sebagai hiburan pribadi. Ketika Edi memainkan gambus dikala sendirian dan tidak dimainkan di panggung pertunjukan, maka kesenian gambus juga memiliki fungsi sebagai hiburan pribadi. Bentuk pertunjukan ini tidak ada penontonnya, penikmatnya adalah si pelantunnya sendiri. Kepuasan akan terasa ketika isi hati tersampaikan lewat lagu yang dinyanyikan.

b. Sebagai Presentasi Estetis

Gambus tunggal Edi berfungsi sebagai presentasi estetis ketika dimainkan di acara-acara hajatan, seperti acara pernikahan dan khitanan. Pertunjukannya memerlukan banyak pendukung yang membutuhkan tambahan biaya. Mulai dari desain panggung, sound system, kostum, lighting, dsb. Selain fungsi primer, gambus tunggal Edi juga memiliki fungsi sekunder sebagai media komunikasi. Fungsi musik sebagai media komunikasi ialah ketika sebuah pertunjukan musik mengkomunikasikan sesuatu yang dimengerti oleh penonton atau penikmatnya. Komunikasi yang terjalin salah satunya bisa lewat bahasa verbal yang termuat di dalam lirik sebuah lagu. Hadirnya lirik di dalam sebuah lagu juga dapat memudahkan tersampaikannya maksud dari sebuah lagu. Pada pertunjukan gambus tunggal Edi Pulampas, lirik yang dibawakan adalah lirik yang berbahasa Lampung. Proses komunikasi dapat berjalan dan terjalin dengan baik, karena penonton atau penikmatnya menggunakan bahasa yang sama. Begitulah komunikasi yang terjalin antara Edi Pulampas dan para penonton. Edi mengkomunikasikan isi hatinya lewat lirik lagu yang dibawakan.

\section{Simpulan}

Edi Pulampas sebagai tokoh gambus di pekon Banjar Negeri, mempopulerkan lima bentuk penyajian gambus, yakni bentuk penyajian gambus tunggal yang dimainkan secara solo, bentuk penyajian lagu gambus yang dipindahkan ke media gitar, bentuk penyajian gambus dengan biola, bentuk penyajian gambus dengan alat musik rebana, accordion, dan gong sebagai iringan tari bedana, sampai pada bentuk penyajian lagu gambus yang didangdutkan, hingga menjadi lagu dangdut Lampung yang khas. Kesenian gambus tunggal Edi Pulampas sampai saat ini masih diminati oleh masyarakat 
Lampung pada umumnya dan masyarakat pekon Banjar Negeri pada khususnya. Minat masyarakat tersebut membuktikan bahwa kesenian gambus tunggal Edi Pulampas masih memiliki peran dan fungsi di dalam masyarakat pendukungnya. Berdasarkan hasil kajian, bahwa kesenian gambus tunggal Edi Pulampas memiliki fungsi dalam masyarakat sebagai hiburan pribadi, presentasi estetis, dan sebagai media komunikasi. Minat masyarakat tehadap kesenian gambus tunggal tidak terlepas dari usaha kreativitas, inovasi, dan edukasi seorang Edi Pulampas yang berjuang terus menerus dalam mengembangkan dan mempopulerkan kesenian gambus tunggal Lampung.

\section{DAFTAR PUSTAKA}

Djohan. 2006. Terapi Musik Teori dan Aplikasi. Yogyakarta: Galangpress.

Hasyimkan. 2011. "Gamolan: Instrumen Musik Tradisional Lampung; Bentuk, Fungsi dan Perkembangannya". Tesis S2 Pengkajian Seni Pertunjukan dan Seni Rupa, Universitas Gadjah Mada Yogyakarta.

Irawan, Ricky. 2008. "Gambus Lampung Pesisir dan Sistem Maqamnya (Kajian Musikologis Fenomena Maqam Dalam Musik Gambus Masyarakat Lampung Pesisir)". Skripsi S1 Seni Musik, ISI Yogyakarta.

Kutoyo, Sutrisno. 1978/1979. Sejarah Kebangkitan Nasional di Daerah Lampung. Jakarta: Departemen
Pendidikan dan Kebudayaan Direktorat Sejarah dan Nilai Tradisional Proyek Penelitian dan Pencatatan Kebudayaan Daerah.

Mahya, Ainun. 2016. Kamus Istilah Bahasa Lampung. Yogyakarta: Frasa Lingua.

Musmal. 2010. Gambus Citra Budaya Melayu. Yogyakarta: Media Kreativa.

Moleong, J. Lexy. 2006. Metodologi Penelitian Kualitatif. Bandung: PT Remaja Rosdakarya.

Pier SJ, Karld Edmund. 1996. Ilmu Bentuk Musik. Yogyakarta: Pusat Musik Liturgi.

Reid, Anthony. 2014. Southeast Asia in the Age of Commerce 1450-1680. Terj. Mochtar Pabotingi. Jakarta: Yayasan Pustaka Obor Indonesia.

Soedarsono, R.M. 2002. Seni Pertunjukan Indonesia di Era Globalisasi. Yogyakarta: Gajah Mada University Press.

2001. Metodologi Penelitian Seni Pertunjukan dan Seni Rupa. Bandung: Masyarakat Seni Pertunjukan Indonesia.

Soekmono, R. 1973. Pengantar Sejarah Kebudayaan Indonesia. Yogyakarta: Yayasan Kanisius.

Sulistijaningtijas, Erlina Pantja. 2013. Sebuah Biografi Prof. Dr. R.M. Soedarsono: Pionir dan Peletak Dasar Lembaga Pendidikan Tinggi Seni Pertunjukan di Indonesia. Yogyakarta: Badan Penerbit ISI Yogyakarta.

Supanggah, $\quad$ Rahayu. 1995. Etnomusikologi. Yogyakarta: Yayasan Bentang Budaya. 
Syamsuri, F., Noor, Tajuddin., Nonsari, R. 1985. Ungkapan Tradisional Sebagai Sumber Informasi Kebudayaan Daerah Lampung. Jakarta: Departemen Pendidikan dan Kebudayaan Proyek Inventarisasi dan Dokumentasi Kebudayaan Daerah.
Taylor, Eric. 1990. Music Theory in Practice Grade 4. London: The Associated Board of the Royal Schools of Music.

1990. Music Theory in Practice Grade 5. London: The Associated Board of the Royal Schools of Music. 